\title{
Design of Slit Loaded Planar and Curved Patch
} Antenna

\author{
Sumanta Kumar Kundu, Pramod Kumar Singhal
}

\begin{abstract}
Slit loaded circularly polarized patch antenna embedded on planar structure and curvature structure were investigated. The curvature effect on slit loaded patch antenna determines the limiting value of radius of curvature to obtain circular polarization. At a certain radius of curvature (ROC) around $131.3 \mathrm{~mm}$, circular polarization have been obtained with axial ratio band width around $15 \mathrm{MHz}$ and return loss bandwidth around $56 \mathrm{MHz}$ compared with $17 \mathrm{MHz}$ and $65 \mathrm{MHz}$ as that of planar structure. The beam width responsible for coverage of planar patch are 104 and 107 degree with respect to 84 degree and 124 degree of curved patch at phi $=0$ and 90 degree respectively.

Keywords : Circular polarization, Curved antenna, Radius of curvature, $3 \mathrm{~dB}$ axial ratio beam width
\end{abstract}

\section{INTRODUCTION}

Microstrip patch antenna is very much useful and mostly suitable antenna in the category of PCB Technology. The L band communication system is suitable to adopt for mixed communication eg fixed and mobile networks. The base station could use this $\mathrm{L}$ band $(1-2 \mathrm{GHz}$ as given by IEEE-ITU) for amateur radio service and digital broadcasting services [1-3]. A survey using simulation on embedded curved structured patch antenna is done to find out the limiting value of radius of curvature (ROC) at which this curved structures behaves as planar antenna and almost gives the same result as of planar [4-13]. Curved structure determines the antenna performance. All the simulated work is performed in CST microwave studio [14]. The slit loaded planar patch is designed for circular polarization and the same concept has been applied to achieve circular polarization in curved structure [8-9].

\section{DESIGN OF SLIT LOADED PLANAR PATCH}

With a square patch of slightly different dimension with one narrow slit having the dimension of width $3.21 \mathrm{~mm}$ and length of $12 \mathrm{~mm}$ at the centre of one edge is etched for circular polarization [4,7-8]. As indicated in the fig.1 (a), the dimension of square patch is $80.26 \mathrm{~mm} \mathrm{X} 79.63 \mathrm{~mm}$ with the thickness of $3.73 \mathrm{~mm}$ of air substrate at a designed frequency of $1.65 \mathrm{GHz}$. The feed point location $8.64 \mathrm{~mm}$ from the centre along the one diagonal [4]. The sense of

Revised Manuscript Received on August 14, 2019

*Correspondence Author

Sumanta Kumar Kundu*, ECE deptt, Maharaja Agrasen Institute of Techlogy, New Delhi, India. Email:sunny_19662002@yahoo.co.in

P K Singhal, Electronics Deptt. 2Madhav Institute of Technology, Gwalior, M.P. India.

(C) The Authors. Published by Blue Eyes Intelligence Engineering and Sciences Publication (BEIESP). This is an open access article under the CC BY-NC-ND license (http://creativecommons.org/licenses/by-nc-nd/4.0/) rotation of circular polarized wave will be changed as per feed position in the other diagonal.

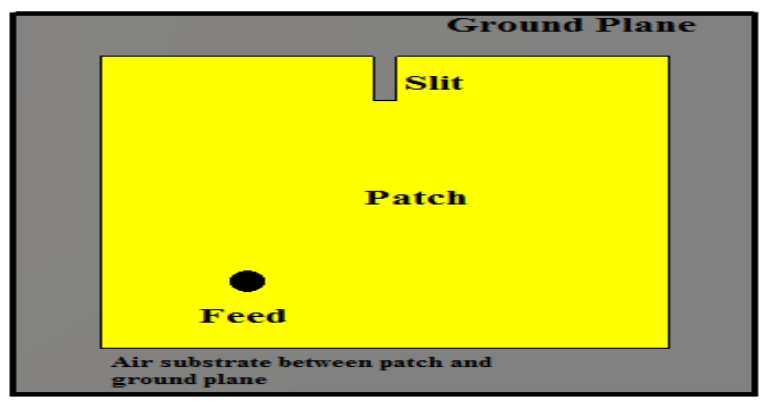

Fig.1: Planar patch

Due to slit in the centre along the upper edge, the $\mathrm{TM}_{10}$ mode have surface current more larger than $\mathrm{TM}_{01}$ mode in other direction and creates 90 degree phase shift, which produces CP polarized wave [10]. As given in [7-9], to obtain $\mathrm{CP}$ radiation, the slit is adjusted to $3.21 \mathrm{~mm} X 12 \mathrm{~mm}$. The simulated axial ratio bandwidth and return loss bandwidth are seen to be $17 \mathrm{MHz}$ and $63 \mathrm{MHz}$ at operating frequency of $1.65 \mathrm{GHz}$ indicated in fig 2. Directive -gain in $\mathrm{YZ}$ and $\mathrm{XZ}$ plane is around $9 \mathrm{dBi}$ with beam width under $3 \mathrm{~dB}$ axial ratio at XZ and YZ plane degree are 107 degree 1nd 104 degree respectively and can be calculated from fig 3 (a) and (b).

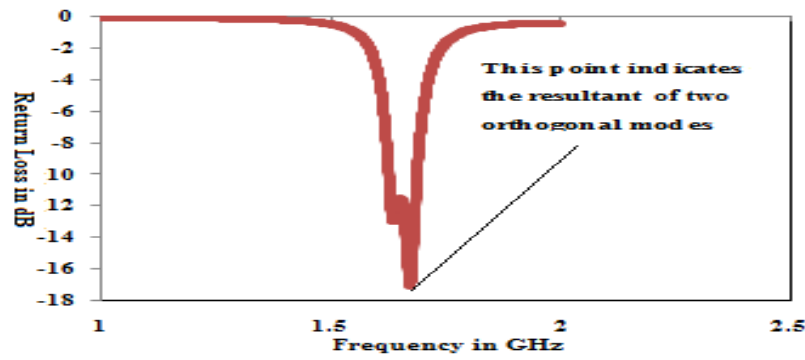

(a)

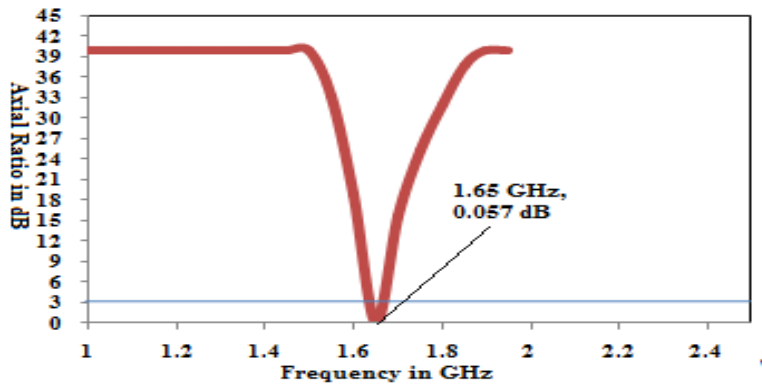

(b)

Fig 2 (a) $3 \mathrm{~dB}$ AR and (b) $S_{11}$ of diagonally fed and slit loaded planar patch antenna at $1.65 \mathrm{GHz}$ 
Design of Slit Loaded Planar and Curved Patch Antenna

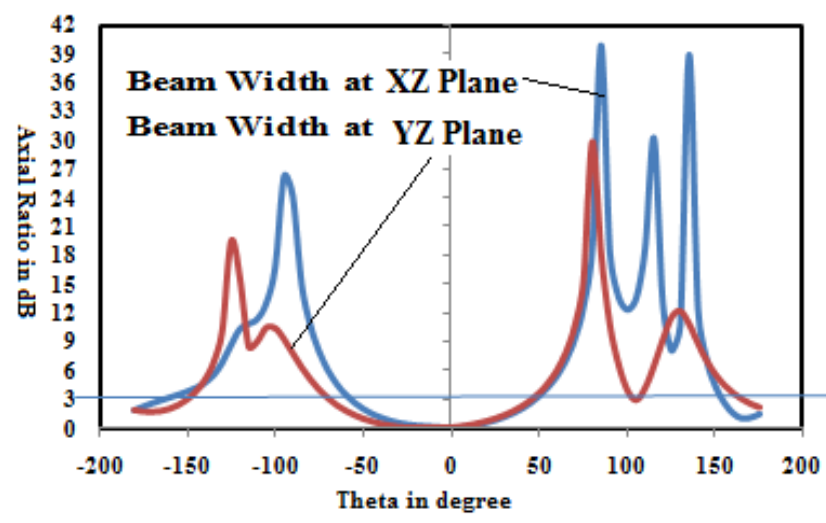

(a)

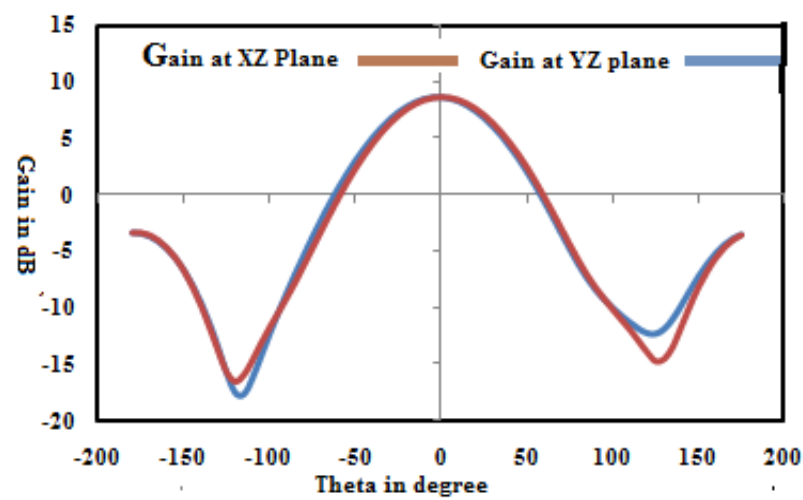

(b)

Fig 3 (a) Beam width and (b) IEEE gain of diagonally fed slit loaded planar patch antenna at $1.65 \mathrm{GHz}$ at (a) $\mathrm{XZ}$ plane and (b) YZ plane
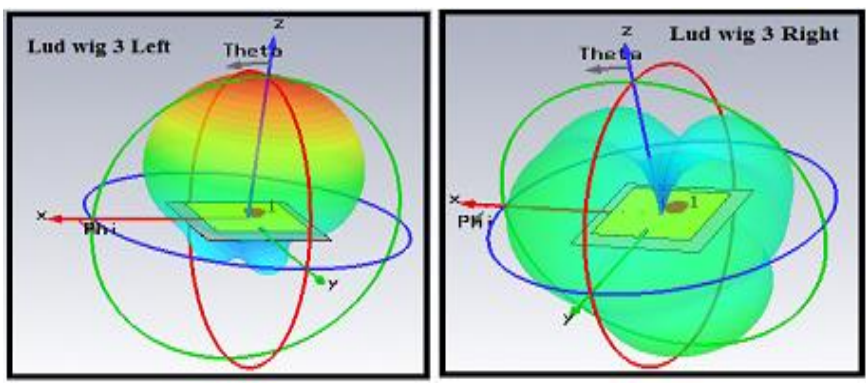

Fig 4 : (a) LHCP radiation (b) RHCP radiation of diagonally fed planar patch antenna at $1.65 \mathrm{GHz}$

The fig 4.(a-b) indicates the LHCP and RHCP pattern of CP planar patch. Hence LHCP dominates over RHCP as shown in above figure.

\section{SLIT LOADED CURVED PATCH}

Patch and slit of same dimension as of planar antenna, is embedded on curved surface of having ground plane and air substrate of $3.73 \mathrm{~mm}$ height and dielectric constant is 1.00059 as shown in fig 5 . The feed point location $8.64 \mathrm{~mm}$ from the centre along the one diagonal $[4,10]$.

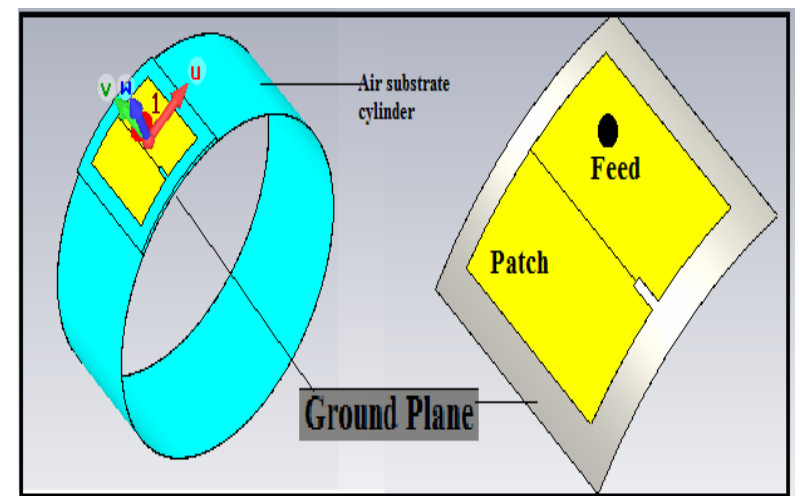

Fig 5: Curved patch design on air substrate designed at $1.65 \mathrm{GHz}$

The sense of rotation of circular polarized wave will be changed as per feed position in the other diagonal. Due to slit in the centre along the upper edge the $\mathrm{TM}_{10}$ mode has surface current more larger than $\mathrm{TM}_{01}$ mode in other direction and creates 90 degree phase shift, which produces circular polarized wave $[7-8,10]$. But the main constraints lie in obtaining circular polarization in curved patch. For that, the radius of curvature is done with the variations of axial ratio and return loss as shown in the fig 6 (a-b). The return loss variation (in fig. 6b) with radius of curvature is found to be very much zigzag because of improper impedance matching of curved surface whereas the variation of axial ratio dictates the improper orthogonality between the two modes $\mathrm{TM}_{10}$ and $\mathrm{TM}_{01}$ at different radius of curvature

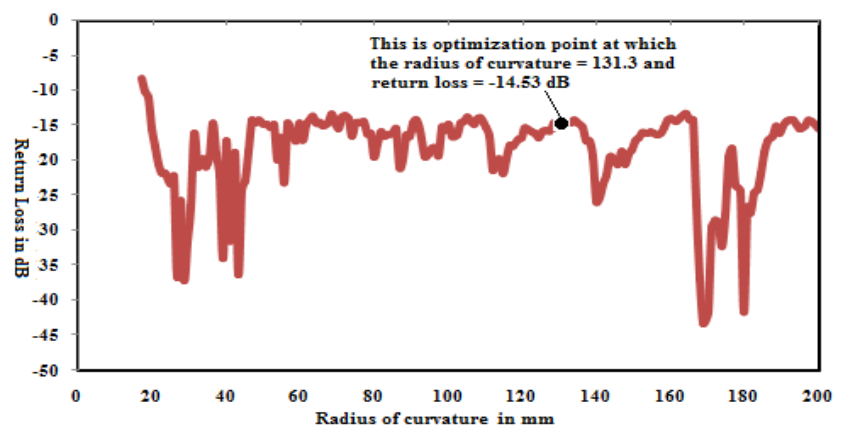

(a)

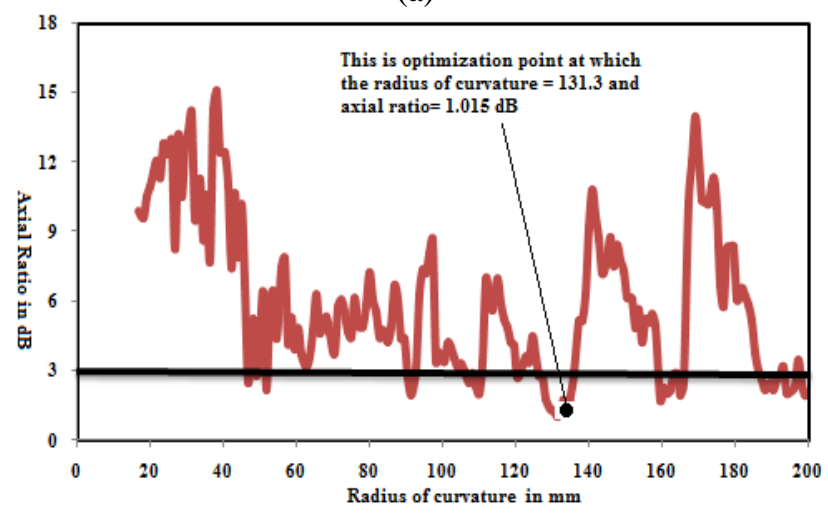

(b)

Fig: 6. (a) Return Loss (b) Axial ratio with the variation of radius of curvature

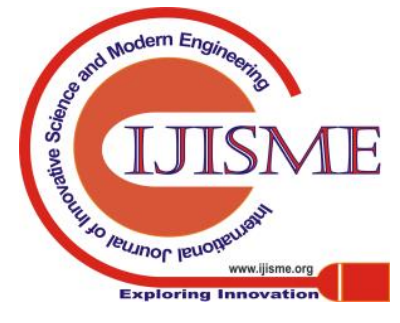


The optimized point for radius of curvature for both the result is decided to be $\mathrm{R}=131.30 \mathrm{~mm}$ and accordingly the following results have been obtained for the patch antenna embedded on curved surface as indicated in fig 7 (a-d).

The simulated axial ratio bandwidth and return loss bandwidth are seen to be $15 \mathrm{MHz}$ and $56 \mathrm{MHz}$ as observed in fig 7 (a-b). The patch is resonating for $1.60 \mathrm{GHz}$ in place of $1.65 \mathrm{GHz}$. In planar antenna both the orthogonal modes were resonating at $1.65 \mathrm{GHz}$ of frequency but when the ground plane and patch bend, due to a large number of basis element function [10-13] and the edge effect due to bending will increase the effective length of the patch [10-13] and frequency decreases to $1.60 \mathrm{GHz}$. There is another reason for decrease in frequency is slit loading. The slit in the curved patch also bends with the curvature, therefore a single slit can be thought of infinite number tiny slit which increases the total effective length of the patch and hence frequency decreases to $1.60 \mathrm{GHz}$ [10-13]. The result in fig 7 (c) and (d) shows that the coverage angle in $\mathrm{XZ}$ plane is 82 degrees and $\mathrm{YZ}$ plane is 124 degrees and the gain in $\mathrm{XZ}$ and $\mathrm{YZ}$ plane seems to be $8.58 \mathrm{dBi}$. As seen in the fig 7, the resonant frequency for slot loaded curved patch decreases due to curvature effect.

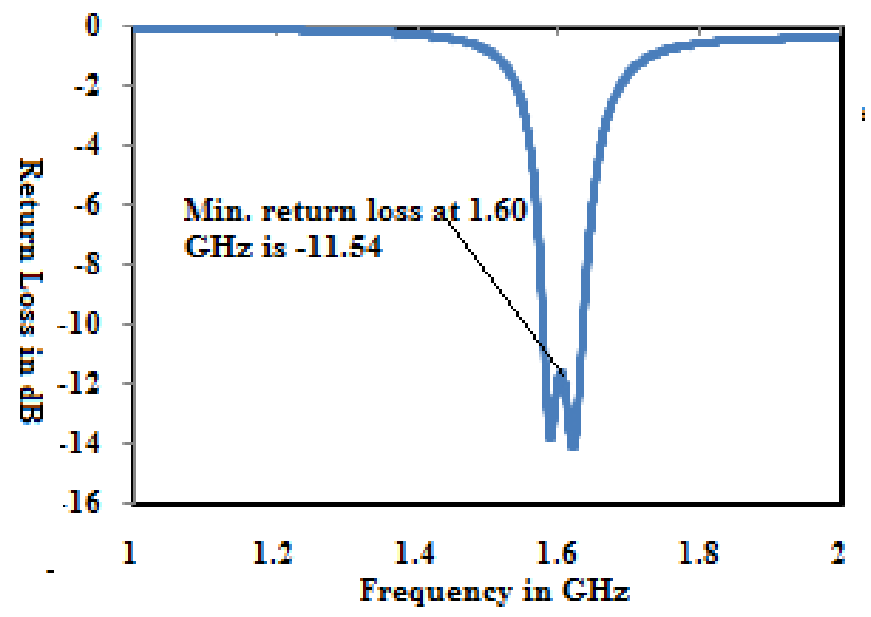

(a)

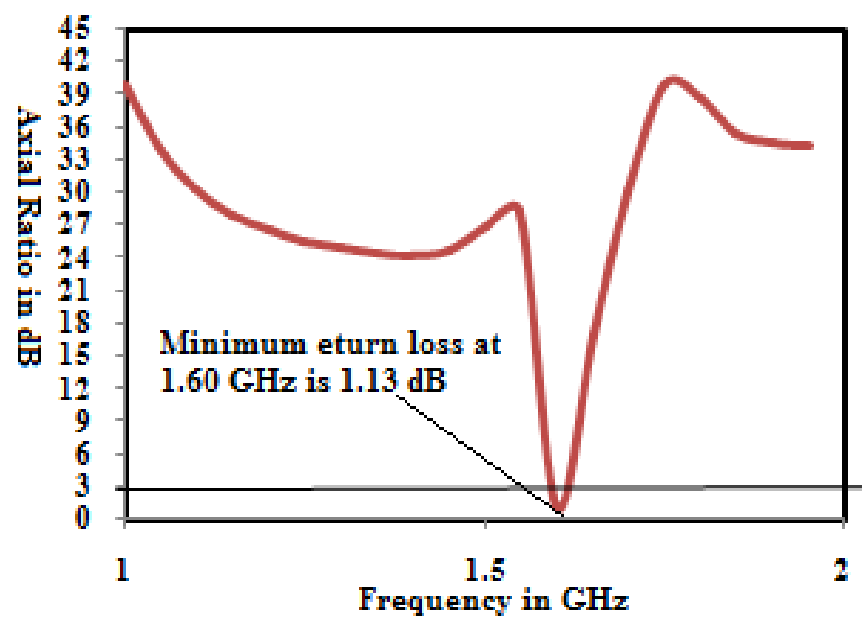

(b)

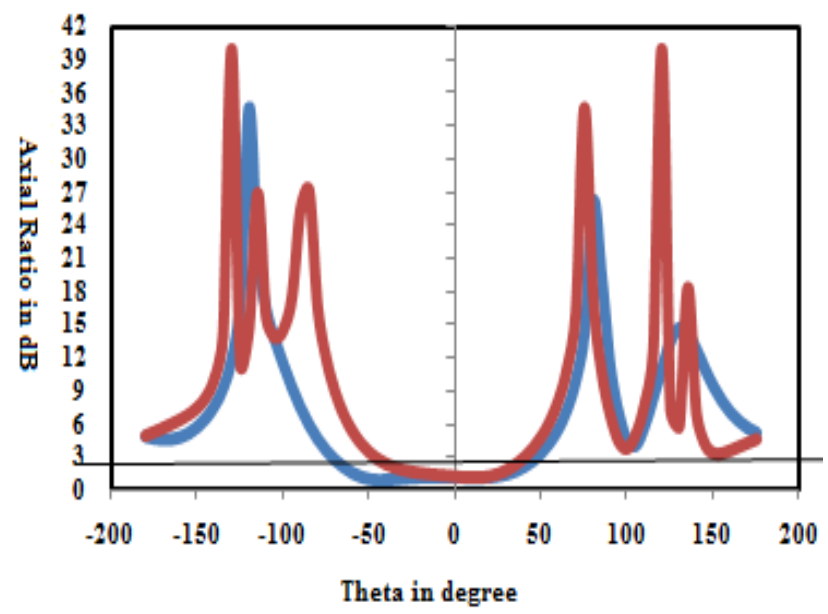

(c)

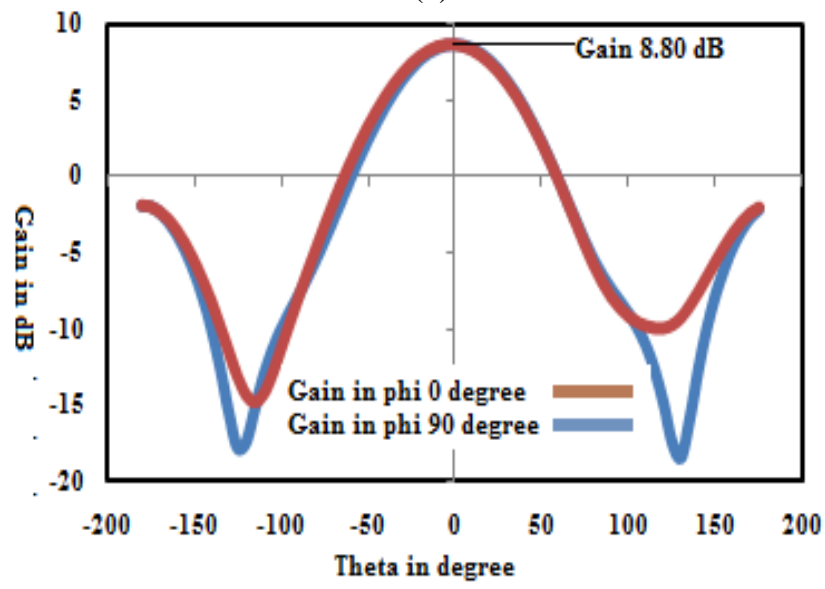

(d)

Fig 7 (a) $S_{11}$ and (b) $3 \mathrm{~dB}$ AR (c) $3 \mathrm{~dB}$ AR beam width at $\mathrm{XZ}$ and $\mathrm{YZ}$ plane and (d) IEEE gain of diagonally fed slit loaded cylindrical antenna at $1.60 \mathrm{GHz}$ at phi $=0$ degree and phi $=90$ degree $($ all result are taken at radius of curvature $=\mathbf{1 3 1 . 2 5} \mathrm{mm}$ )

The fig 8 (a) and (b) shows the LHCP and RHCP radiation pattern of CP planar patch. The LHCP is dominated over RHCP in the figure 8.

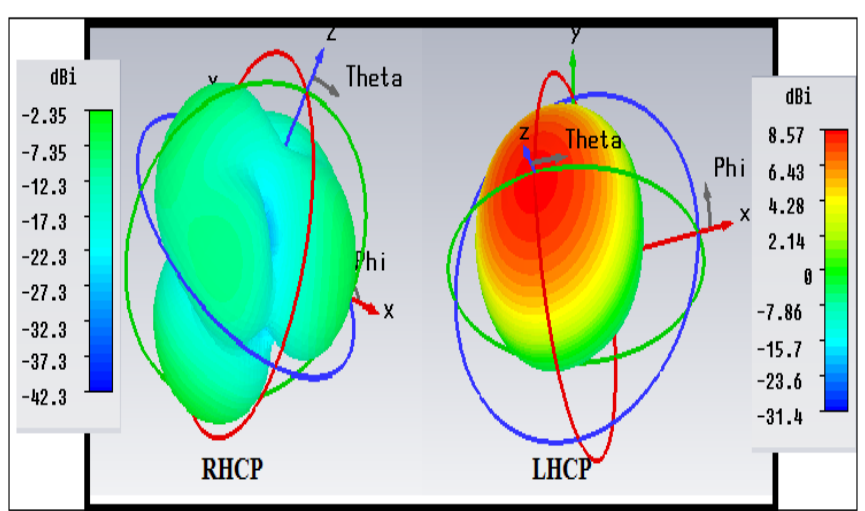

Fig 8 : (a) LHCP radiation (b) RHCP radiation of diagonally fed planar patch antenna at $1.60 \mathrm{GHz}$

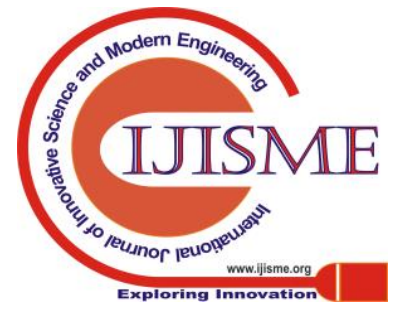




\section{Design of Slit Loaded Planar and Curved Patch Antenna}

\section{CONLUSION}

A circularly polarized slit loaded patch antenna on planar and curved surfaces has been designed and simulated. The variations of $A R$ and $S_{11}$ with curvature have been studied. The slit loaded curved structure achieves $56 \mathrm{MHz}$ impedance \& $17 \mathrm{MHz}$ AR bandwidth. The $3 \mathrm{~dB}$ axial ratio beam width obtained at $1.60 \mathrm{GHz}$ is around 84 and 124 degree in $\mathrm{XZ}$ and $\mathrm{YZ}$ plane..Hence the angular scanning coverage of this patch antenna on curve surface is comparable to planar antenna.

\section{ACKNOWLEDGEMENTS}

This work would not have been completed without the software support and encouragement of department of Electronics Engg in Madhav Institute of technology and Science, Gwalior, MP, India.

\section{REFERENCES}

1. Gupta, Samir Dev," Design of Microstrip Antenna conformable to both planar and cylindrical surfaces for Aircraft Systems" Shodhganga : a reservoir of Indian theses @ INFLIBNET.

2. C. A. Balanis, “Antenna Theory, Analysis and Design,” John Wiley \& Sons, New York, second edition 1997.

3. Keith R. Carver, James W. Mink, "Microstrip antenna technology" IEEE transactions on antennas and propagation",vol.29, no. 1, January 1981.

4. Sin Keng Lee, A. Sambell, E. Korolkiewicz, and S. F. Ooi, “analysis and design of a circular-polarized nearly square-patch antenna using a cavity model" microwave and optical technology letters / Vol. 46, No. 4, August 202005

5. K.M.Mak, Kwai Man Luk, "A Circularly Polarized Antenna With Wide Axial Ratio Beamwidth", IEEE Transactions on Antennas and Propagation ( Volume: 57 , Issue: 10 , Oct. 2009 ).

6. Nasimuddin, Y. S. Anjani, and A. Alphones, " A Wide-Beam circularly polarized Asymmetric-Microstrip Antenna " IEEE Transactions on Antennas and Propagation 2015.

7. K. L.Wong,W. H. Hsu, and C. K.Wu, "Single-feed circularly polarized microstrip antenna with a slit," Microwave Opt. Technol. Lett. 18, 306-308, July 1998.

8. Kin Lu wong, "compact broadband antenna" John Wiley \& Sons, Inc.

9. R. E. Munson, "Conformal Microstrip Antennas and Microstrip Phased Arrays", IEEE Trans. Antenna Propagate., vol. AP-22, no. 1, January 1974, pp. 74-78.

10. Kin-Lu Wong and Shyh-Yeong Ke,"Cylindrical-Rectangular Microstrip Patch Antenna for Circular Polarization”, IEEE transactions on antennas and propagation, vol. 41, no. 2, February 1993.

11. J. S. Dahele, R. J. Mitchell, K. M. Luk, and K. F. Lee, "Effect of curvature on characteristics of rectangular patch antenna," Electron.Lett., vol. 23, pp. 748-749, July 1987.

12. C. M. Krowne, "Cylindrical rectangular microstrip antenna." IEEE Trans. Antennas Propagat., vol. AP-31. pp. 194-199, 1983.

13. K M Luk and K F Lee, "Analysis of the cylindrical -Rectangular patch antenna”, IEEE Trans. Antennas Propagat., vol. 37, no.2 Feb 1989.

14. CST microwave Studio suite

\section{AUTHORS PROFILE}

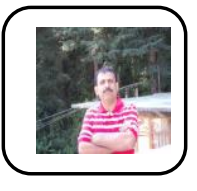

Sumanta Kumar kundu, is a $\mathrm{PhD}$ student in Electronics Department in Madhav Institute of technology and Science, Gwalior, MP. His area of interest lies in microwave and optical domain. He is working to develop and to design the microstrip patch antenna on non planar structure.

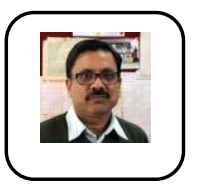

Dr. Pramod Kumar, Singhal is working as a professor in Department of Electronics Engg in Madhav Institute of technology and Science, Gwalior, MP. He has more than 30 years of teaching experience in MITS Gwalior India. He has Published more than 150 research papers, which include papers in IEEE Transaction, international and national journals, international and national conference. Present interest includes research and teaching in microwave engineering, communication system, microwave antennas, computer aided design of microwave integrated circuit and software development. 